\title{
Cyberbullying Ditinjau dari Traits Kepribadian Conscientiousness Pada Siswa Kelas XI SMA Swasta Bodhicita Medan
}

\section{Cyberbullying Viewed fromTraits of Conscientiousness Personality on the Senior High School Grade 2 of Bodhicita Private School Medan}

\author{
Velda*, Achmad Irvan Dwi Putra \& Sarinah \\ Jurusan Psikologi, Fakultas Psikologi,Universitas Prima Indonesia
}

Diterima: Mei 2019; Disetujui: Juli 2019; Dipublish: Agustus 2019

\begin{abstract}
*Coresponding Email: veliro29@gmail.com
Abstrak

Penelitian ini bertujuan untuk mengetahui hubungan antara traits kepribadian conscientiousness dengan cyberbullying. Hipotesis yang diajukan dalam penelitian ini adalah ada hubungan negatif antara traits kepribadian conscientiousness dengan cyberbullying. Subjek penelitian yang digunakan dalam penelitian ini adalah siswa kelas XI SMA Swasta Bodhicita Medan yang berjumlah 119 orang. Data diperoleh dari skala untuk mengukur traits kepribadian conscientiousness dan cyberbullying. Perhitungan dilakukan dengan melakukan uji asumsi yang terdiri dari uji normalitas dan uji linearitas. Analisis data yang digunakan adalah menggunakan korelasi Product Moment melalui bantuan SPSS 20 for Windows. Hasil analisis data menunjukkan koefisien korelasi sebesar -0.575 dan nilai signifikansi sebesar $0.000(\mathrm{p}<0.05)$. Hasil penelitian ini menunjukkan bahwa sumbangan yang diberikan variabel traits kepribadian conscientiousness terhadap cyberbullying sebesar 33.1 persen, selebihnya 66.9 persen dipengaruhi oleh faktor lain yang tidak diteliti. Dari hasil penelitian ini dapat ditarik kesimpulan bahwa hipotesis penelitian ada hubungan negatif antara traits kepribadian conscientiousness dengan cyberbullying dapat diterima
\end{abstract}

Kata Kunci: Traits Kepribadian Conscientiousness, Cyberbullying

\begin{abstract}
This study aims to determine the relationship between conscientiousness personality traits and cyberbullying. The hypothesis proposed in this study is that there is a negative relationship between the traits of conscientiousness personality and cyberbullying. The research subjects used in this study were class XI students of Bodhicita Private High SchoolMedan, totaling 119 people. Data is obtained from a scale to measure the traits of conscientiousness and cyberbullying personality. Calculations are carried out by conducting an analysis prerequisite test (assumption test) consisting of a normality test and a linearity test. Analysis of the data used is using Product Moment correlation through SPSS 20 for Windows. The results of data analysis showed a correlation coefficient of -0.575 and a significance value of 0.000 ( $p$ $<0.05)$. The results of this study indicate that the contribution given to the conscientiousness personality traits variable towards cyberbullying is 33.1 percent, the remaining 66.9 percent is influenced by other factors not examined. From the results of this study it can be concluded that the research hypothesis there is a negative relationship between the traits of conscientiousness personality and acceptable cyberbullying.
\end{abstract}

Keywords: Traits of Conscientiousness Personality, Cyberbullying

How To Cite: Velda, Sarinah \& Putra, A.I.D. (2019). Cyberbullying ditinjau dariTraits Kepribadian Conscientiousness pada Siswa kelas XI SMA Swasta Bodhicita. Journal of Education, Humaniora and Social Sciences (JEHSS). 2 (1): 64 -73. 


\section{PENDAHULUAN}

Informasi dan teknologi sekarang ini merupakan faktor yang amat dominan dalam masyarakat hampir di seluruh dunia. Memang bukan pada masa kini informasi dan teknologi penting bagi kehidupan manusia. Sejak semula informasi sudah menentukan perkembangan individu dan masyarakat. Sulit membayangkan manusia dapat mengenal diri dan sekitarnya serta memprediksi situasi yang akan dihadapi tanpa informasi. Informasi dan teknologi adalah dua hal yang tak mungkin dipisahkan. Berkat kemajuan teknologi, maka informasi menyebar secara cepat dan telah mampu mengubah bentuk kehidupan masyarakat. (Sitompul, 2016)

Menurut Supriyanto (2009) mendefinisikan Internet adalah gabungan dari jaringan komputer yang berada di seluruh dunia yang membentuk suatu sistem jaringan informasi global. Rafiudin (2006) mengemukakan bahwa internet dengan berbagai kapabilitas dan aneka layanan yang ditampilkan dapat segera menjangkau ke pelosok dunia dengan kurun waktu yang relatif pendek, suatu mekanisme penghamburan informasi, media interaksi dan berkolaborasi di antara manusia dan komputer tanpa dibatasi oleh letak geografis dan waktu. Pada periode berikutnya pengembangan internet semakin serius dan terbuka. Saat ini ribuan partisipan, baik organisasi, vendor, maupun individu dari berbagai belahan dunia turut terlibat di dalamnya.

Berdasarkan data statistik yang diperoleh dari APJII (Asosiasi Penyelenggara Jasa Internet Indonesia), Jumlah pengguna Internet di Indonesia tahun 2016 adalah 132,7 juta user atau sekitar 51,5\% dari total jumlah penduduk Indonesia sebesar 256,2 juta. Pengguna internet terbanyak ada di pulau Jawa dengan total pengguna 86.339.350 user atau sekitar $65 \%$ dari total penggunan Internet. Jika dibandingkan penggunana Internet Indonesia pada tahun 2014 sebesar 88,1 juta user, maka terjadi kenaikkan sebesar 44,6 juta dalam waktu 2 tahun (2014 - 2016). (www.apjii.or.id)

Kementrian Komunikasi dan Informatika (Kemekominfo), menyatakan bahwa 95\% pengguna internet dari 63 juta orang Netizen Indonesia saat ini, menggunakan internet untuk mengakses situs jejaring sosial. Hasil survey tersebut juga menyatakan u bahwa mayoritas pengguna internet di Indonesia adalah pribadi yang berada dalam rentang usia 18-25 tahun atau biasanya dikategorikan sebagai kelompok usia dewasa awal (49\%) dan diikuti oleh usia 28-35 tahun (33,8\%).(www.kominfo.go.id) 
Juvonen dan Gross (2008) mengungkapkan bahwa berkembangnya penggunaan teknologi komunikasi khususnya pada remaja, dunia maya menjadi wadah baru yang beresiko bagi aksi kekerasan. Efek negatif dalam menggunakan internet yang dapat menyebabkan timbulnya perilaku kekerasan pada dunia internet disebut dengan cyberbullying. Cyberbullying adalah bentuk agresi yang terjadi melalui komputer pribadi (misalnya, email dan pesan instan) atau ponsel (mis. Perpesanan teks), (Wang, dkk dalam Betts, 2016), sedangkan menurut Patchin \& Hinduja (dalam Betts, 2016) menyatakan bahwa cyberbullying merupakan perilaku seseorang atau kelompok secara sengaja dan berulang kali melakukan tindakan yang menyakiti orang lain melalui komputer, telepon seluler, dan alat elektronik.

Penelitian-penelitian sebelumnya menunjukkan faktor yang mempengaruhi cyberbullying adalah traits kepribadian conscientiousness. Penelitian sebelumnya yang dilakukan oleh oleh Larasati \& Fitria (2016) terhadap 81 siswa Sekolah Menengah Atas Negri di Yogyakarta menunjukkan adanya hubungan negatif antara kepribadian conscientiousness dengan perilaku cyberbullying. Semakin tinggi skor dimensi kepribadian conscientiousness maka akan menurunkan kecenderungan perilaku cyberbullying. Sebaliknya, semakin rendah skor dimensi kepribadiaan conscientiousness maka akan menaikkan kecenderungan perilaku cyberbullying.

Menurut Feist (2008) menyatakan bahwa conscientiousness merupakan ciri kepribadian yang teratur, terkontrol, rapi, ambisius, fokus pada pencapaian dan disiplin diri. Individu yang memiliki nilai tinggi pada conscientiousness adalah orang yang pekerja keras, teliti, tepat waktu, dan tekun. Sebaliknya pada individu yang rendah dalam conscientiousness cenderung berantakan, lalai, malas, dan tak bertujuan dan lebih mudah menyerah apabila dihadapkan pada kesulitan. Widiger (2017) juga mengungkapkan bahwa conscientiousness merupakan rujukan pada sebuah konstruk yang dicerminkan pada kecenderungan control diri, tanggung jawab pada orang lain, pekerja keras, teratur, dan kepatuhan pada peraturan. Penelitian ini bertujuan untuk mengetahui hubungan antara traits kepribadian conscientiousness dengan cyberbullying.

Berdasarkan dari semua uraian diatas, peneliti sangat tertarik dalam melakukan penelitian untuk mengetahui hubungan traits kepribadian conscientiousness dengan cyberbullying pada siswa kelas XI SMA Swasta Bodhicita Medan. Hal itu dikarenakan pada saat peneliti melakukan observasi dan wawancara terhadap salah satu siswi di 
Bodhicita Medan. Siswi tersebut memiliki kegemaran merias wajahnya. Pada saat siswi tersebut memposting sebuah foto di media sosialnya, teman teman sekelasnya banyak memberikan komentar negatif di postingannya dengan menghina fisik siswi tersebut dengan mengatakan riasannya jelek, nampak tua, jelek, gemuk, dan sebagainya. Siswi tersebut tersinggung dengan perkataan teman-temannya dan membalas komentar temannya dengan kata-kata yang kasar. Siswi ini sering mencurahkan isi hatinya di media sosial jika sedang mengalami masalah seperti pada saat orang tuanya berantam, ataupun pada saat mendapatkan barang yang diinginkan seperti tas merek ternama maka siswi tersebut suka memposting di media sosialnya. Terkadang postingannya menjadi sorotan teman-teman lainnya karena dianggap terlalu memamerkan sehingga terjadi aksi saling membalas satu dengan yang lainnya di kolom komentar dengan menggunakan kata-kata yang kasar. Penelitian ini penting bagi siswa siswi Bodhicita agar mereka yang mempunyai memiliki kepribadian yang rapi, rajin dan teratur mengajak teman teman yang memiliki kepribadian kurang teratur, malas belajar, berantakan, dan nakal untuk saling bersosialisasi antara satu dan yang lainnya sehingga dapat mengurangi kecenderungan terjadinya perilaku cyberbullying. Siswa dapat meningkatkan kepribadian conscientiousness dengan cara memperbanyak sosialisasi dengan orang lain sehingga memiliki sifat yang lebih hangat, lebih peka, lebih membantu dan lebih bersahabat agar siswa tersebut dapat menjadi individu yang lebih baik dimasa depan dan membanggakan orang tua.

Berdasarkan pemaparan di atas, maka hipotesis yang diajukan dalam penelitian ini adalah ada hubungan negatif antara antara traits kepribadian conscientiousness dengan cyberbullying dengan asumsi semakin tinggi antara traits kepribadian conscientiousness yang dimiliki siswa, maka akan semakin rendah cyberbullying. Sebaliknya semakin rendah traits kepribadian conscientiousness yang dimiliki siswa, maka akan semakin tinggi cyberbullying.

\section{METODE PENELITIAN}

Populasi dalam penelitian ini adalah siswa SMA kelas XI SMA Bodhicita Medan yang berjumlah 176 orang. Metode pengambilan sampel yang digunakan adalah stratified random sampling (acak terstratifikasi), merupakan teknik pengambilan sampel dari populasi yang berstrata secara random atau acak. ( Soewadji, 2012). Jumlah sampel yang digunakan adalah 119 orang siswa siswi kelas XI SMA Bodhicita Medan. 
Alat pengumpulan data yang digunakan dalam penelitian ini adalah dengan menggunakan metode pembagian skala untuk mengukur cyberbullying dan conscientiousness. Jenis skala yang digunakan adalah skala Likert. Dengan skala Likert, Dengan skala Likert, maka variabel yang akan diukur dijabarkan menjadi indikator variabel. Kemudian indikator atau komponen-komponen tersebut dijadikan titik tolak untuk menyusun item-item instrument yang berupa pertanyaan atau pernyataan (Sugiyono, 2010). Skala yang digunakan dalam penelitian ini menggunakan empat alternatif jawaban yaitu SS (sangat setuju), S (setuju), TS (tidak setuju), dan STS (sangat tidak setuju), yang mana pernyataanfavourablemakamengandungnilai-nilai yang positif, SS (sangat setuju) diberikan bobot 4 (empat), S (setuju) dengan bobot 3 (tiga), TS (tidak setuju) dengan bobot 2 (dua), dan STS (sangat tidak setuju) dengan bobot 1 (satu). Sistem penilaian sebaliknya, jika pernyataan unfavourable yaitu SS (sangat setuju) diberikan bobot 1 (satu), S (setuju) dengan bobot 2 (dua), TS (tidak setuju) dengan bobot 3 (tiga), dan STS (sangat tidak setuju) dengan bobot 4 (empat).

Skala cyberbullying disusun berdasarkan pengukuran cyberbullying menggunakan skala cyberbullying yang meliputi aspek/dimensi verbal/written, visual/sexual, dan social eclusion yang dikemukakan oleh Lee, dkk (2015). Skala traits kepribadian conscientiousness disusun berdasarkan diungkapkan dengan skala Traits kepribadian Conscientiousness yang disusun berdasarkan Lee dan Ashton (dalam Widiger, 2017) menyusun aspek conscientiousness terbagi atas empat aspek, yaitu: organization, diligence, perfectionism, dan prudence.

Pelaksanaan uji validitas dan reliabilitas alat ukur dilakukan pada siswa SMA Methodist Tanjung Morawa. Sebanyak 98 siswa SMA Methodist Tanjung Morawa menjadi sampel. Pada skala conscientiousness, hasil uji coba alat ukur menunjukkan bahwa 36 dari 50 aitem dinyatakan sahih. Uji validitas dalam tryout penelitian ini menggunakan metode corrected item total correlation berdasarkan $r$ minimal 0,3 dengan nilai $r$ bergerak 0,312-0,644. Dalam skala penelitian ini diperoleh realibilitas Alpha Cronbach sebesar 0,920. Pada skala cyberbullying, hasil uji coba alat ukur menunjukkan bahwa 24 dari aitem dinyatakan sahih. Uji validitas dalam tryout penelitian ini menggunakan metode corrected item total correlation berdasarkan r minimal 0,3 dengan nilai $r$ bergerak 0,302-0,615. Dalam skala penelitian ini diperoleh realibilitas Alpha 
Cronbach sebesar 0,865. Dengan hasil ini diperoleh arti bahwa skala ini layak digunakan sebagai alat pengumpulan data dalam penelitian ini.

HASIL DAN PEMBAHASAN

\section{Analisa Deskriptif Cyberbullyingdan Traits Kepribadian Conscientiousness}

Tabel 1. Statistik Deskriptif

\begin{tabular}{llll}
\hline Descriptive Statistics & & & \\
\hline & $\mathrm{N}$ & Mean & Std. Deviation \\
Cyberbullying & 119 & 44,94 & 7,083 \\
Traits kepribadian conscientiousness & 119 & 108,17 & 13,154
\end{tabular}

Tabel 1 merupakan statistik deskriptif variabel cyberbullying dantraits kepribadian conscientiousness. Tabel ini menunjukkan variabel cyberbullying memiliki nilai rata-rata 44,94 dengan standar deviasi 7,083. Sedangkan pada variabel traits kepribadian conscientiousness, memiliki nilai rata-rata 108,17 dengan standar deviasi 13,154.

Tabel 2. Kriteria tingkat cyberbullying dantraits kepribadian conscientiousness

\begin{tabular}{lllll} 
Variabel & Rentang Nilai & Kategori & Jumlah (n) & Persentase \\
\hline Cyberbullying & $\mathrm{x}<48$ & Rendah & 76 & $63,87 \%$ \\
& $48 \leq \mathrm{x}<72$ & Sedang & 43 & $36,13 \%$ \\
Traits kepribadian conscientiousness & $\mathrm{x} \geq 72$ & Tinggi & 0 & $0 \%$ \\
& $\mathrm{Jumlah}$ & & 119 & $100 \%$ \\
& $\mathrm{x}<72$ & Rendah & 1 & $0,84 \%$ \\
& $72 \leq \mathrm{x}<108$ & Sedang & 56 & $47,06 \%$ \\
& $\mathrm{x} \geq 108$ & Tinggi & 62 & $52,1 \%$ \\
& Jumlah & & 119 & $100 \%$ \\
\hline
\end{tabular}

Tabel 2 merupakan kriteria tingkat cyberbullying dantraits kepribadian conscientiousness. Tabel ini menunjukkan rata-rata cyberbullying berada pada kategori tinggi rendah dengan presentase sebesar 63,87\%. Sedangkan rata-rata traits kepribadian conscientiousness berada pada kategori tinggi dengan presentase sebesar 52,1\%.

Penelitian ini adalah penelitian korelasional yang digunakan untuk mengetahui ada atau tidaknya korelasi antara traits kepribadian conscientiousness dengan cyberbullying. Namun sebelum dilakukan uji korelasi, peneliti melakukan uji asumsi terlebih dahulu untuk menentukan jenis statistik parametik atau non-parametik yang akan digunakan untuk uji korelasi.

Uji normalitas dilakukan agar dapat mengetahui apakah setiap data variabel penelitian telah menyebar secara normal atau tidak. Uji normalitas sebaran dalam penelitian ini diuji dengan menggunakan uji Kolmogorov Smirnov Test. Data dikatakan 
berdistribusi normal jika $\mathrm{p}>0,05$ (Priyatno, 2011). Uji normalitas pada variabel cyberbullying diperoleh koefisien $\mathrm{KS}-\mathrm{Z}=0,744$ dengan Sig sebesar 0,637 untuk uji 2 (dua) arah (two tailed) dan sedangkan penelitian ini memiliki hipotesis satu arah, sehingga yang dipakai adalah uji 1 (satu) arah (one tailed) sebesar 0,3185 ( $\mathrm{p}>0,05$ ), yang memiliki arti bahwa data pada variabel cyberbullying memiliki sebaran atau berdistribusi tidak normal. Uji normalitas yang dilakukan terhadap variabel kepribadian conscientiousness diperoleh koefisien $\mathrm{KS}-\mathrm{Z}=$ 0,533 dengan Sig sebesar 0,939 untuk uji 2 (dua) arah (two tailed) dan sedangkan penelitian ini memiliki hipotesis satu arah, sehingga yang dipakai adalah uji 1 (satu) arah (one tailed) sebesar 0,4695 ( $\mathrm{p}>0,05$ ), yang memiliki arti bahwa data pada variabel traits kepribadian conscientiousness memiliki sebaran atau berdistribusi normal.

Tabel 3. Hasil Uji Normalitas

\begin{tabular}{llllll}
\hline Variabel & SD & KS-Z & Sig. & p & Keterangan \\
\hline Cyberbullying & 7,083 & 0,744 & 0,3185 & $\mathrm{p}>0,05$ & Sebaran normal \\
Traits kepribadian Conscientiousness & 13,154 & 0,533 & 0,4695 & $\mathrm{p}>0,05$ & Sebaran normal \\
\hline
\end{tabular}

Dari hasil uji normalitas data, didapat hasil data berdistribusi normal pada salah satu variabel, jadi uji korelasi yang digunakan dalam penelitian ini adalah korelasi Spearman rho. Berdasarkan hasil analisis korelasi antara traits kepribadian conscientiousness dengancyberbullying, diperoleh koefisien korelasi Spearman rho sebesar $-0,575$ dengan sig sebesar $0,000(p<0,05)$. Hasil tersebut menunjukkan bahwa adanya hubungan negative antara traits kepribadian conscientiousness dengan cyberbullying. Dari hasil perhitungan tersebut, maka hipotesis yang diajukan dalam penelitian ini menunjukkan adanya hubungan negative antara traits kepribadian conscientiousness dengan cyberbullying diterima. Hasil penelitian pada 119 siswa XI SMA Bodhicita Medan yang menjadi partisipan peneliti diperoleh bahwa ada hubungan negatif antara traits kepribadian conscientiousness dengan cyberbullying dengan koefisien korelasi spearman rho sebesar $r=0,575$ dan p sebesar 0,000, artinya semakin tinggi kepribadian conscientiousness maka semakin rendah perilaku cyberbullying, dan sebaliknya semakin rendah kepribadian conscientiousness maka semakin tinggi perilaku cyberbullying 


\section{Cyberbullying danTraits Kepribadian Conscientiousness pada Siswa}

Hasil penelitian yang menyatakan adanya hubungan antaratraitskepribadian conscientiousness dengan cyberbullying sejalan dengan pendapat Larasati dan Fitria, (2016), yang menunjukkan adanya hubungan yang signifikan antara traitskepribadian conscientiousness dengan cyberbullying. Traits kepribadian conscientiousness mempunyai pengaruh yang signifikan terhadap cyberbullying, selain faktor-faktor lain yang mempengaruhi cyberbullying, seperti kepribadian extrovert dan introvert, kematangan emosi dan sebagainya.

Penelitian ini menunjukkan perilaku cyberbullying pada siswa kelas XI SMA Bodhicita Medan yang masuk dalam terdapat 76 siswa $(63,87$ persen) yang memiliki perilaku cyberbullying rendah, terdapat 43 siswa (36,13 persen) yang memiliki perilaku cyberbullying sedang, dan terdapat 0 siswa (0 persen) yang memiliki perilaku cyberbullying tinggi. Berdasarkan penjelasan di atas maka dapat disimpulkan bahwa rata-rata siswa penelitian memiliki perilaku cyberbullying rendah.

Berdasarkan hasil observasi dan wawancara menunjukkan bahwa perilaku cyberbullying kategori rendah sebanyak 76 siswa dengan 63,87 persenterlihat dari dimensi verbal/written dimana siswa berbicara dengan kata-kata yang kasar, nada marah yang mempunyai maksud untuk menyakiti temannya.

Siswa yang termasuk kategori perilaku cyberbullying sedang sebanyak43 siswa dengan 36,13 persen. Hal ini ditunjukkan darihasil wawancara dengan beberapa siswa menyatakan kadang mereka menngirim pesan dengan kata-kata yang jahat, memasang foto teman tanpa sepengetahuan temannya, dan ada juga yang menghiraukan perkataan teman yang tidak disukainya dalam kelas tersebut. Perilaku di atas berkenaan dengan salah satu aspek perilaku cyberbullying yaitu verbal/written, visual/sexual, dan social exclusion.

Penelitian kepribadian conscientiousness pada siswa SMA Bodhicita Medan yang masuk dalam katagori rendah sebanyak 1 (satu) siswadengan persentase0,84 persen, memiliki kepribadian conscientiousness rendah, kemudian terdapat 56 siswa dengan persentase 47,06 persen yang memiliki kepribadian conscientiousness sedang, sedangkan siswa yang memiliki kepribadian conscientiousness tinggi berjumlah 62 siswa dengan 52,1 persen. Berdasarkan penjelasan di atas maka dapat disimpulkan bahwa rata-rata siswa penelitian memiliki kepribadian conscientiousness tinggi. 
Penelitian yang dilakukan terhadap siswa SMA Bodhicita menunjukkan sebanyak 1 siswa dengan persentase 0,84 persen yang memiliki kepribadian conscientiousness rendah. Berdasarkan penelitian siswa yang memiliki kepribadian conscientiousnss rendah sering meletakkan barang pada sembarang tempat, memiliki motivasi rendah dan kurang teliti. Perilaku di atas berkenaan dengan dimensi organization, deligence, dan perfectionism.

Siswa yang termasuk dalam kategori kepribadian conscientiousness sedang adalah sebanyak 56 siswa dengan 47,06 persen . Hal ini dapat ditunjukkan dari hasil wawancara yang menyatakan meletakkan barang pada tempatnya, belajar dengan giat untuk mendapatkan nilai yang tinggi dan disiplin dengan peraturan yang ada. Perilaku diatas berkenaan dengan dimensi organization dan deligence.

Siswa dalam kategori kepribadian conscientiousness tinggi sebanyak 62 siswa dengan persentase 52,1 persen dapat terlihat dari beberapa siswa mengerjakan tugas pada saat jam istirahat, mendengarkan guru dengan seksama, memiliki motivasi tinggi dalam belajar, berhati hati dalam mengerjakan ujian dan membuang sampah pada tempatnya. Perilaku diatas berkenaan dengan organization, deligence, prudence, dan perfectionism.

\section{SIMPULAN}

Ada hubungan negatif antara kepribadian conscientiousness dengan perilaku cyberbullying. Hal ini dibuktikan sengan nilai korelasi Spearman rho (r) sebesar - 0,575 dengan p sebesar 0,000 ( $\mathrm{p}<0,5)$ dengan asumsi bahwa semakin tinggi kepribadian conscientiousness maka semakin rendah perilaku cyberbullying, dan sebaliknya semakin rendah kepribadian conscientiousness maka semakin tinggi perilaku cyberbullying

\section{DAFTAR PUSTAKA}

Ahmadi \& Hermawan. (2013). E-Business \& E-Commerce. Yogyakarta: Andi.

Azwar, S. (2006). Penyusunan Skala Psikologi. Edisi 1, Cetakan ke 8. Yogyakarta: Pustaka Pelajar.

Arikunto, S. (2013). Prosedur Penelitian Suatu Pendekatan Praktik. Jakarta: Rineka Cipta

Betts, L. (2016). Cyberbullying: Approaches, Consequences and Interventions. United Kingdom: Palgrave Macmillan UK.

Feist, J. \& Feist, G. J. (2008). Theories of personality, 7ed. New York: McGraw-Hill Inc.

Juvonen, J. \& Gross, E. F. (2008). Extending the School Grounds?-Bullying Experiences in Cyberspace. Journal of School Health, American School Health Association. Vol. 78, No. 9

Larasati, A. \& Fitria, M. (2016). KecenderunganPerilakuCyberbullying DitinjaudariTraits dalamPendekatan Big Five Personality padaSiswaSekolahMenengahAtasNegeri di Kota Yogyakarta. JurnalPsikologilntegratif. Vol. 4, No. 2, 2016.

Priyatno, D. (2010). Paham Analisa Statistic Data dengan SPSS. Yogyakarta: Mediakom.

h乘://mahesainstitute.web.id/ojs2/index.php/jehss 
Rafiudin, R. (2006). Protokol-Protokol Esensial Internet. Yogjakarta: Andi.

Sitompul, E M. (2006). GerejaMenyikapiPerubahan. Jakarta: GunungMulia.

Supriyanto. (2009). Teknologi Informasi \& Komunikasi SMP Kelas IX. Ghalia Indonesia Printing

Widiger, T. A. (2017). The Oxford Handbook of the Five Factor Model. New York: Oxford University Press.

Apjii. (2016). Data Statistik. Diakses pada 13 April 2017 dari https://apiii.or.id/downfile/file/surveipenetrasiinternet2016.pdf

Kominfo. (2013). Pengguna Internet di Indonesia. Diakses pada 13 April 2017 dari https://kominfo.go.id/index.php/content/detail/3415/Kominfo+:+Pengguna+Internet+di+Indonesi $\underline{\text { a+63+Juta+Orang/0/berita satker }}$ 